\title{
MONITORAMENTO DE QUALIDADE DE ÁGUAS SUPERFICIAIS EM SUB-BACIAS HIDROGRÁFICAS: UMA PROPOSTA DE FLUXO DE TRABALHO
}

\author{
MONITORING OF SURFACE WATER QUALITY IN SUB-BASINS: A \\ WORKFLOW PROPOSAL
}

\author{
Felipe David Georges Gomes ${ }^{1}$; Leonardo Mira do Nascimento Ferro²; \\ Patrícia Alexandra Antunes ${ }^{3}$; Ana Paula Marques Ramos ${ }^{4}$ \\ ${ }^{1}$ Universidade do Oeste Paulista - UNOESTE, Mestrando pelo Programa de Pós- \\ Graduação em Meio Ambiente e Desenvolvimento Regional \\ E-mail: felipedgg@yahoo.com.br \\ ${ }^{2}$ Centro Universitário da Fundação Educacional Inaciana, Graduando pelo Curso de \\ Engenharia Química \\ E-mail: miraleonardo@outlook.com \\ ${ }^{3}$ Universidade do Oeste Paulista - UNOESTE, Docente do Curso de Química de \\ Presidente Prudente \\ E-mail: antunes@unoeste.br \\ ${ }^{4}$ Universidade do Oeste Paulista - UNOESTE, Docente da Pós-Graduação em Meio \\ Ambiente e Desenvolvimento Regional \\ E-mail: anaramos@unoeste.br
}

RESUMO - Esse trabalho teve como objetivo descrever um fluxo de trabalho que abrange do processo de definição de pontos amostrais até a coleta e conservação de amostras de água para avaliação e monitoramento de qualidade de águas superficiais em sub-bacias hidrográficas. Os procedimentos metodológicos basearam-se em revisão de literatura e para ilustrar a aplicação do fluxo de trabalho, realizou-se um estudo de caso no córrego Limoeiro, localizado entre os limites municipais de Presidente Prudente e Álvares Machado, no estado de São Paulo. Como resultado obteve-se mapas de localização da área de estudo, uso e ocupação do solo, e do zoneamento urbano do município de Presidente Prudente, que possibilitaram a definição dos pontos amostrais com a finalidade de avaliar e/ou monitorar a sub-bacia hidrográfica do córrego Limoeiro. Observou-se o uso das geotecnologias como facilitadoras na resolução de problemas.

Palavras-chave: Análise de qualidade de água; impacto ambiental; fluxo de trabalho; sub-bacia hidrográfica.

Recebido em: 17/08/2018 Revisado em: 27/08/2018 Aprovado em: 29/08/2018
ABSTRACT - This work aimed was describe a workflow from the process the defining sampling points up to the water samples collection and conservation for evaluation and monitoring in sub-basins. The methodological procedures they were based on literature review and to illustrate the workflow application, a case study was carried in the Limoeiro stream, located in the municipalities of Presidente Prudente and Álvares Machado, São Paulo state. As result, we obtained location 
maps of the study area, land use and land cover, and the urban zoning of the municipality of Presidente Prudente, which enabled the definition of sampling points for the purpose of the sub-basin Limoeiro stream evaluating and/or monitoring. The use geotechnology as a facilitator in solving problems was observed.

Keywords: Water quality analysis; environmental impact; workflow; sub-basin. 


\section{INTRODUÇÃO}

A degradação e poluição sofrida pelos recursos hídricos está intimamente relacionada ao mau planejamento e mau gerenciamento destes recursos, e afeta diretamente a quantidade e qualidade de água disponível e compatível com as mais variadas formas de uso. Para um gerenciamento efetivo dos recursos hídricos é necessária a avaliação qualitativa e quantitativa frequente, no intuito de conhecer devidamente suas condições, potencialidades e os prováveis problemas resultantes de contaminação e poluição. (TUNDISI; MATSUMURA-TUNDISI, 2008). De acordo com os autores supracitados, o monitoramento qualitativo e quantitativo dos recursos hídricos é uma ferramenta inicial oportuna na elaboração de uma base de dados útil e segura, que possibilita a identificação de regiões e áreas mais ou menos contaminadas, de modo a estabelecer estratégias ao planejamento e ao gerenciamento desses recursos.

Planejar e gerenciar os recursos hídricos são desafios extremamente difíceis, devido as grandes extensões e a complexidade dos sistemas hídricos. Assim, para auxiliar neste processo se faz necessária a descentralização dessas unidades hídricas para bacias hidrográficas, haja visto que, conforme Zahed Filho (2012) "a bacia hidrográfica é a menor unidade espacial de gerenciamento dos recursos hídricos". Todavia, subdividir essas bacias hidrográficas, ainda com vastas extensões, facilita o processo de planejamento e gerenciamento dos recursos hídricos. Além disso, subdividir uma bacia hidrográfica em componentes, isto é, sub-bacias hidrográficas, permite pontuar os problemas difusos, contribuindo à identificação de diversos fatores, tais como o foco de degradação, a característica dos processos de degradação e o grau de responsabilidade das atividades existentes nesta área. (FERNANDES; SILVA, 1994).

No que tange o monitoramento hídrico dessas áreas, antes do início das amostragens é necessário definir claramente os objetivos e delinear programas de amostragem, através de uma verificação cuidadosa do recurso a ser analisado, quais variáveis serão analisadas (indicadores), como serão analisadas, os locais onde serão observadas, a frequência de observação, a duração do monitoramento e a precisão com que cada variável deve ser observada (PAIVA; PAIVA, 2001; THEOBALD et al., 2007). Ademais é pertinente a seleção dos métodos analíticos, equipamentos e métodos de coleta e preservação das amostras, planejar as amostragens, e se necessário reavaliar a metodologia (CETESB, 2011). Definido esses itens o passo subsequente é a coleta das amostras, análises in loco e/ou laboratoriais, e interpretação dos dados. Vale salientar, que o plano de amostragem deve considerar para o monitoramento, o uso dos recursos hídricos, a natureza, a área de influência e as características da área de estudo (CETESB, 2011). Nesse sentido, determinar os pontos amostrais constitui etapa fundamental, já que além da estreita relação com o objetivo, implicará em tempo e recurso financeiro (RODRIGUES et al., 2016).

Diante do exposto, objetiva-se descrever um fluxo de trabalho que abrange do processo de definição de pontos amostrais até a coleta e conservação de amostras de água para avaliação e o monitoramento de qualidade de águas superficiais em sub-bacias hidrográficas.

\section{METODOLOGIA}

Os procedimentos metodológicos basearam-se em revisão de literatura sobre o tema. O fluxo de trabalho proposto é composto por três grandes etapas: definição de pontos amostrais, coleta e conservação de amostras de água. A etapa de definição dos pontos amostrais se subdivide em fases, as quais estão ilustradas no fluxograma apresentado na Figura 1. 
Figura 1. Fluxograma para a definição dos pontos de amostragem de água

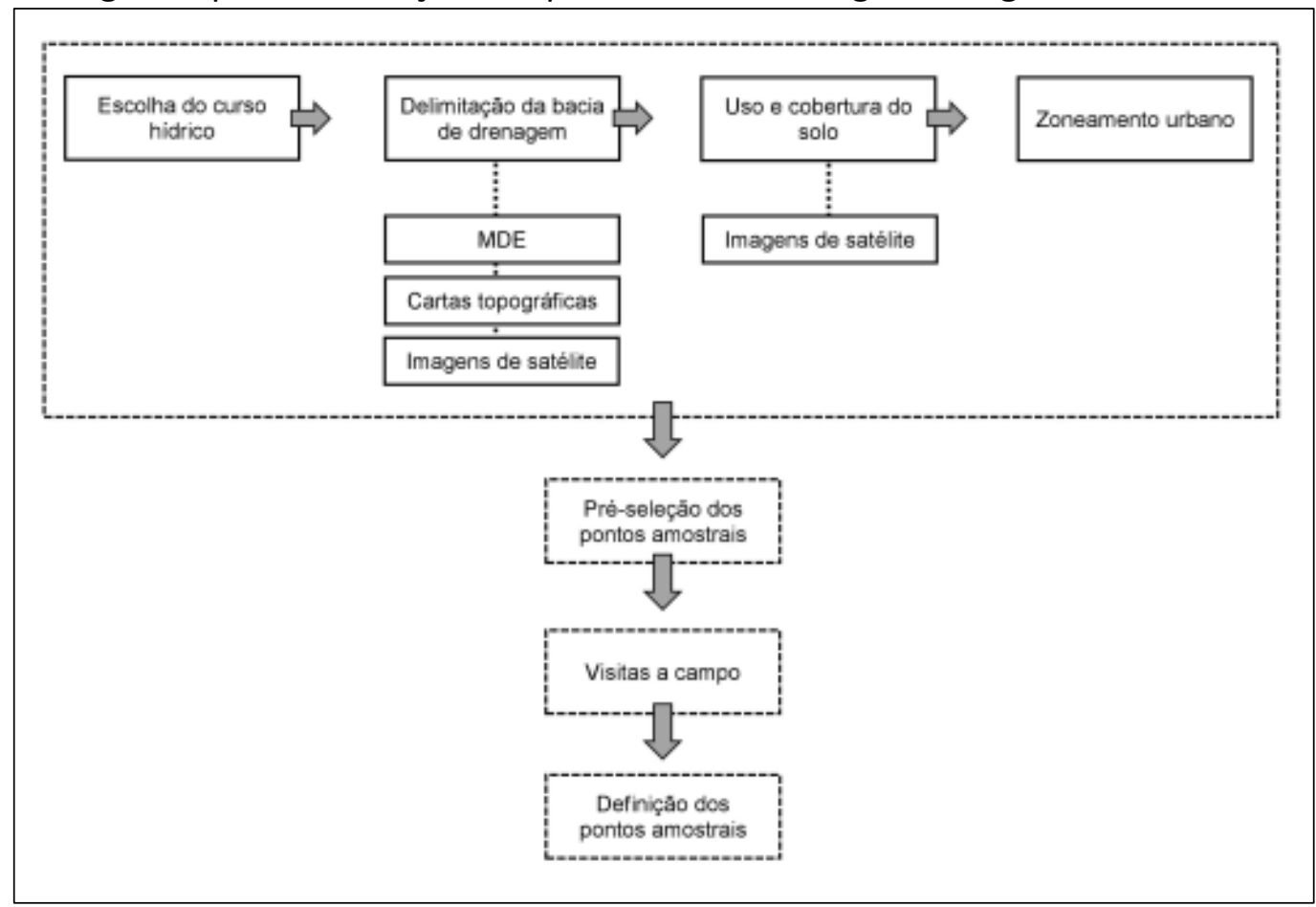

Fonte: Autores (2018)

\subsection{Definição dos pontos amostrais}

\subsubsection{Delimitação da área de interesse}

A partir do estabelecimento de um curso hídrico de interesse, o fluxo de trabalho se inicia com a delimitação da área de drenagem (bacia hidrográfica) desse curso. Essa delimitação pode ser realizada em software livre de Sistema de Informação Geográfica (SIG), tal como o QGIS 2.18.14. Para isso, sugere-se o uso, de cartas topográficas, na escala 1:50.000, disponibilizadas pelo Instituto Brasileiro de Geografia e Estatística (IBGE); Modelo digital de Elevação (MDE) SRTM (Shuttle Radar Topography Mission), com resolução espacial de 30 metros, do ano de 2014, e, também, imagens do satélite Sentinel $2 B$, com resolução espacial de 10 metros e escala aproximada de 1:25.000, ambos hospedadas no site da United States Geological Survey (USGS). Tais dados serão utilizados.

A bacia de drenagem é delimitada automaticamente a partir do MDE SRTM, no QGIS 2.18, com o complemento TauDEM (Terrain Analysis Using Digital Elevation Models). Enquanto que as cartas topográficas do IBGE e as imagens do satélite Sentinel-2B podem ser utilizadas para uma inspeção visual do resultado da delimitação da bacia.

\subsubsection{Seleção dos pontos de coleta}

Com a área da bacia delimitada, devese gerar um mapa de uso e ocupação do solo. Neste caso, as imagens Sentinel-2B são uma excelente opção por serem gratuitas e de boa resolução espacial (10 metros), porém, podese recorrer às imagens da série Landsat, que embora sejam de menor resolução espacial (30 metros), são disponibilizadas desde 1984. O mapa de uso e ocupação do solo pode ser gerado usando o plugin "Semi-Automatic Classification Plugin" (SCP), dentro do QGIS 2.18.14. Nesse plugin é possível, também, verificar o nível de acerto da classificação das imagens, isto é, a precisão do mapa de uso e ocupação do solo.

O mapa de zoneamento urbano das cidades abrangidas pela área de interesse (bacia hidrográfica) pode ser outro dado importante para auxiliar na definição dos pontos de coleta de água. Assim, mediante uma análise visual e da sobreposição entre os mapas de zoneamento urbano e uso e ocupação do solo, pode-se pré-definir um 
conjunto de pontos para coleta de amostras de águas superficiais.

\subsubsection{Visitas a campo}

As visitas em campo aos possíveis pontos de coleta de água é uma etapa fundamental para permitir o registro fotográfico e geográfico de cada ponto, além de uma descrição das características das áreas ao seu entorno. Sugere-se o uso do aplicativo livre mobile Topographer, desenvolvido pela empresa S.F. Applicality $L t d$., para o registro das coordenadas geográficas dos pontos. Esse aplicativo pode ser instalado em um smartphone convencional, o qual permite, também, o registro fotográfico. A descrição das características de cada ponto pode ser realizada em pranchetas ou no bloco de notas do smartphone.

Essa estratégia de visita a campo e coleta de informações sobre os pontos prédefinidos para a coleta de água é baseada na CETESB (2011), que afirma a necessidade de:

Elaboração de croqui com a
localização dos possíveis pontos de
coleta; Visita à área de estudo para
georreferenciamento dos locais de
coleta por meio de GPS ("Global
Positioning System"), levantamento
fotográfico com as características
locais e contato com as pessoas do
local a fim de se obter dados
adicionais que confirmem ou
esclareçam os dados preliminares
levantados; Verificação das vias de
acessos, bem como a situação das
mesmas, tempo necessário para a
realização dos trabalhos,
disponibilidade de apoio local para
armazenamento e transporte de
material de coleta e amostras,
avaliando possíveis limitações ou
interferências.

\subsubsection{Definição dos pontos amostrais}

A definição dos pontos amostrais deve, então, ser realizada com base na consideração de fatores, tais como, descrição geral de cada ponto, registros fotográficos, distribuição espacial dos pontos na bacia hidrográfica de interesse, a acessibilidade aos pontos, tempo requerido na coleta e nos procedimentos laboratoriais, e recursos financeiros disponíveis tanto para a coleta quanto análise laboratorial.

\subsection{Procedimento de coleta e conservação das amostras de água}

A prioridade por realizar as coletas nos pontos amostrais em um mesmo dia e a exigência de algumas análises laboratoriais serem realizadas no prazo máximo de 24 horas após a coleta, exige um planejamento prévio e cuidadoso para a coleta e a conservação das amostras de água. Assim, com o auxílio dos softwares de SIG e do google maps é possível estabelecer uma rota de trabalho.

Ainda para o dia das coletas, deve-se separar prancheta, folhas com pauta e identificação dos pontos de coleta, etiquetas, canetas esferográficas, canetas permanentes, balde, corda, galocha, luvas e equipamentos para medição de alguns parâmetros in loco, como pHmetro, condutivímetro e medidor portátil de oxigênio dissolvido.

Quanto à conservação das amostras, frascos de vidro âmbar devem ser separados e esterilizados previamente, servindo como coletores. Na hipótese de não ser possível chegar ao centro do leito do rio com estes frascos para coleta de amostras, aconselhase o uso de baldes de alumínio que devem ser lavados previamente com a água do próprio rio, onde será coletada a amostra.

Coletada as amostras, elas devem ser armazenadas em caixas térmicas com gelo, de preferência gelo reutilizável. Não havendo a possibilidade por algum motivo de usar esse tipo de gelo, recomenda-se acondicionar o gelo em garrafas de politereftalato de etileno (PET) evitando no descongelamento, uma possível contaminação das amostras.

\section{RESULTADOS}

Para ilustrar a aplicação do fluxo de trabalho, realizamos um estudo de caso no córrego Limoeiro, localizado entre os limites municipais de Presidente Prudente e Álvares 
Machado, no oeste do estado de São Paulo, e pertencente a Unidade de Gerenciamento de Recurso Hídricos do Pontal do Paranapanema (UGRHI 22). Conforme Longley et al. (2013) "quase tudo que acontece, acontece em algum lugar" assim conhecer o local onde algo ocorre é fundamental, principalmente quando se trabalha com questões ambientais. Portanto, é necessária a espacialização da área de estudo. Assim, a elaboração do mapa de localização da bacia hidrográfica do córrego Limoeiro permitiu mapear esta área em termos de país, estado e municípios (Figura 2). Além disso, por meio de ferramentas do software de SIG foi possível levantar dados como a área, que é estimada em $92,16 \mathrm{~km}^{2}$; o comprimento do rio principal (córrego Limoeiro), aproximadamente $24 \mathrm{~km}$; e o comprimento total dos cursos hídricos, 124,95 km.

Figura 2. Mapa de localização da sub-bacia hidrográfica do córrego Limoeiro.

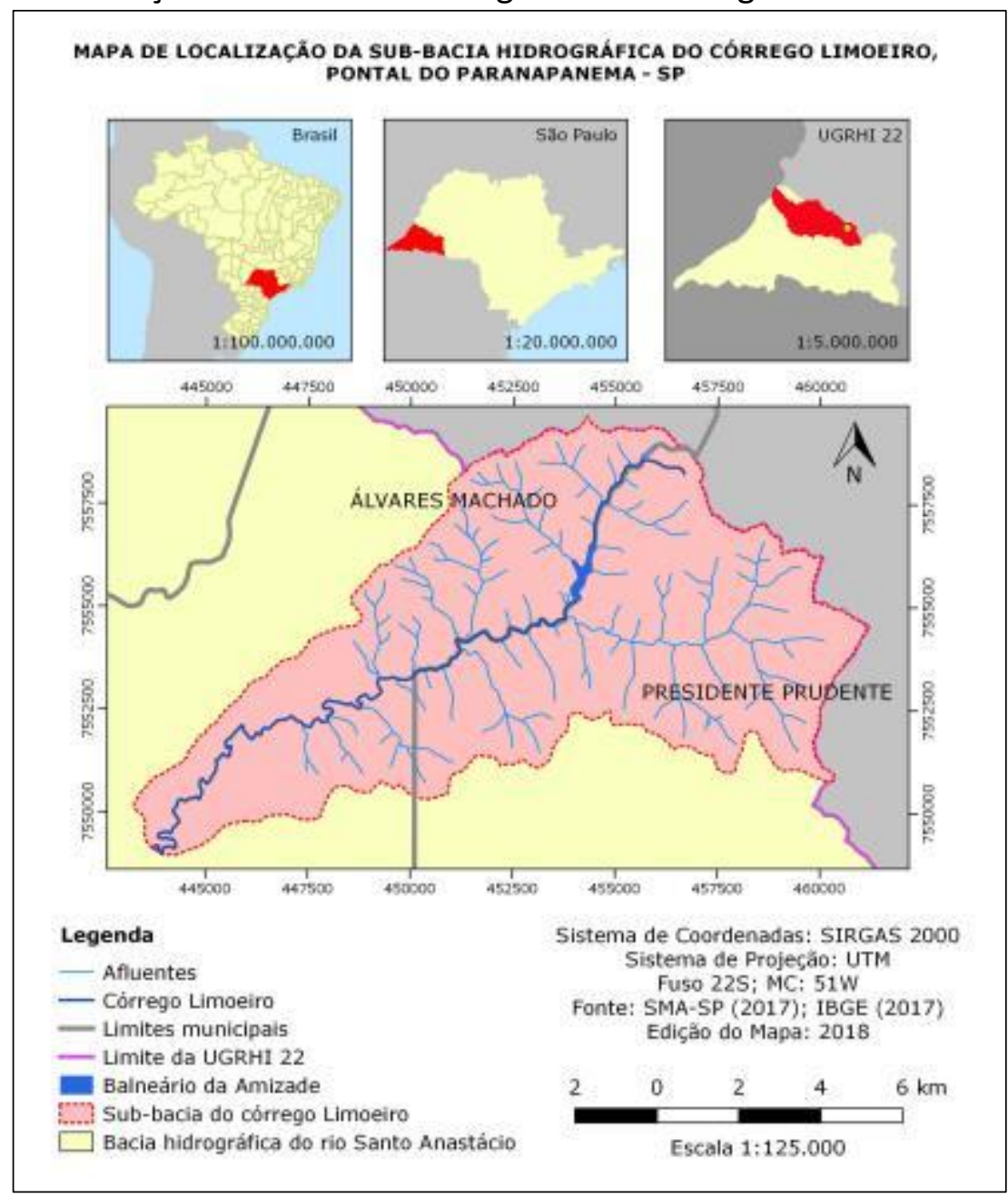

Fonte: Autores (2018).

A Figura 3 ilustra o uso e ocupação do solo na bacia durante o mês de novembro de 2017. Neste mapa é possível perceber principalmente áreas urbanizadas e de vegetação herbácea. As áreas urbanizadas concentram-se no perímetro urbano de Presidente Prudente e Álvares Machado, e em pontos do perímetro rural onde existem áreas construídas, como por exemplo casas ou ainda construções como a da estação de tratamento de esgoto do Limoeiro. A vegetação herbácea é composta principalmente por pastagens, indicando uma grande produção agropecuária na região.

$\mathrm{Na}$ área caracterizada como solo exposto podemos citar e considerar áreas em preparo para plantio ou pós colheita, áreas para implantação de construções urbanas, e áreas que simplesmente tiveram sua 
vegetação suprimida, estando suscetíveis a processos erosivos.

O mapa de uso e ocupação do solo permite ainda, observar algumas áreas com vegetação arbórea preservada ao longo dos rios, auxiliando na proteção das águas superficiais. Todavia em grande parte da extensão dos cursos hídricos, as áreas de preservação permanente encontram-se degradadas, possibilitando o aumento de processos erosivos, poluição e contaminação das águas através do escoamento superficial.

$\mathrm{Na}$ Figura 4, vemos o zoneamento urbano do município de Presidente Prudente, que dá subsídios para entendermos as possíveis fontes de contaminação urbana. Chamamos a atenção para as áreas de zona especial, onde encontram-se curtumes, frigoríficos, cemitérios, dentre outros com grande potencial poluidor.

No mapa da Figura 5 vemos a definição dos pontos escolhidos para posterior coleta de amostras de água. No presente estudo de caso, foram pré-definidos 32 pontos de coleta e realizada a coleta em 11 desses pontos, considerando os critérios estabelecidos na seção de metodologia. Os pontos foram numerados de 1 a 11, considerando o fluxo hídrico da bacia hidrográfica. No Quadro 1 podemos verificar imagens dos pontos amostrais e uma descrição das características de cada ponto.

A rota para as campanhas de coleta foi definida de acordo com o tempo de acesso mais curto entre um ponto e outro. Considerando o ponto de encontro entre os pesquisadores, definiu o início pelo ponto 6, na sequência os pontos $7,5,4$. Os próximos pontos escolhidos foram sequencialmente 2 , 3 e 1 . Do ponto 1 , a opção de trajeto escolhido foi o ponto 11, 10, 9 e 8, uma vez que 0 ponto 8 encontra-se próximo ao destino final para a entrega das amostras.

É importante destacar que a coleta das amostras de água foi realizada em conformidade com o guia nacional de coleta e preservação de amostras: água, sedimento, comunidades aquáticas e efluentes líquidos (CETESB, 2011). Quanto a análise dessas águas, imediatamente após a coleta, o material foi levado para laboratório, onde puderam ser submetidas às análises físicoquímicas e microbiológicas seguindo os procedimentos da American Public Health Association (APHA, 2012). 
Figura 3. Mapa de uso e ocupação do solo.

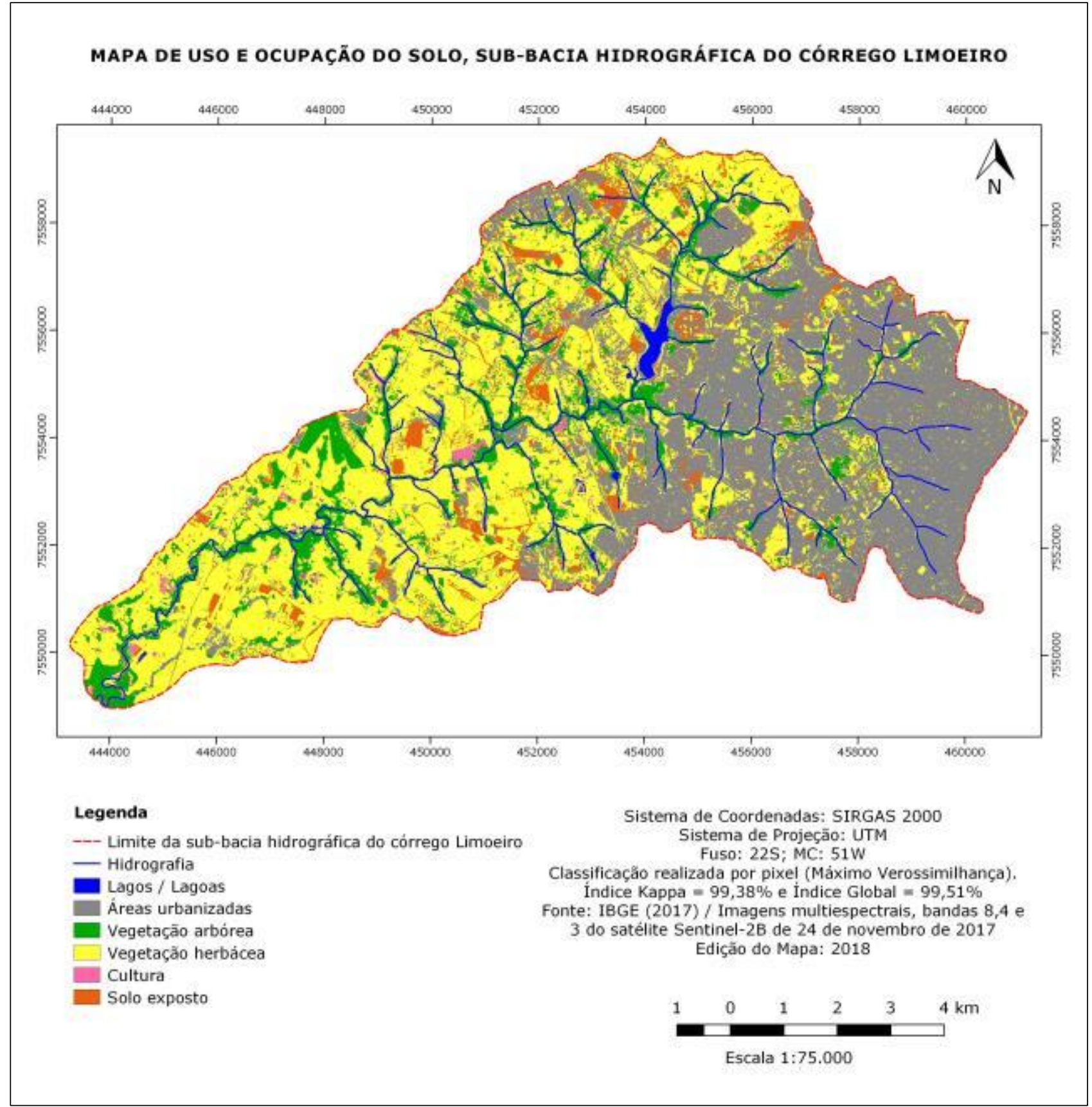

Fonte: Autores (2018). 
Figura 4. Imagem do mapa de zoneamento urbano sobreposto na sub-bacia hidrográfica do córrego Limoeiro.

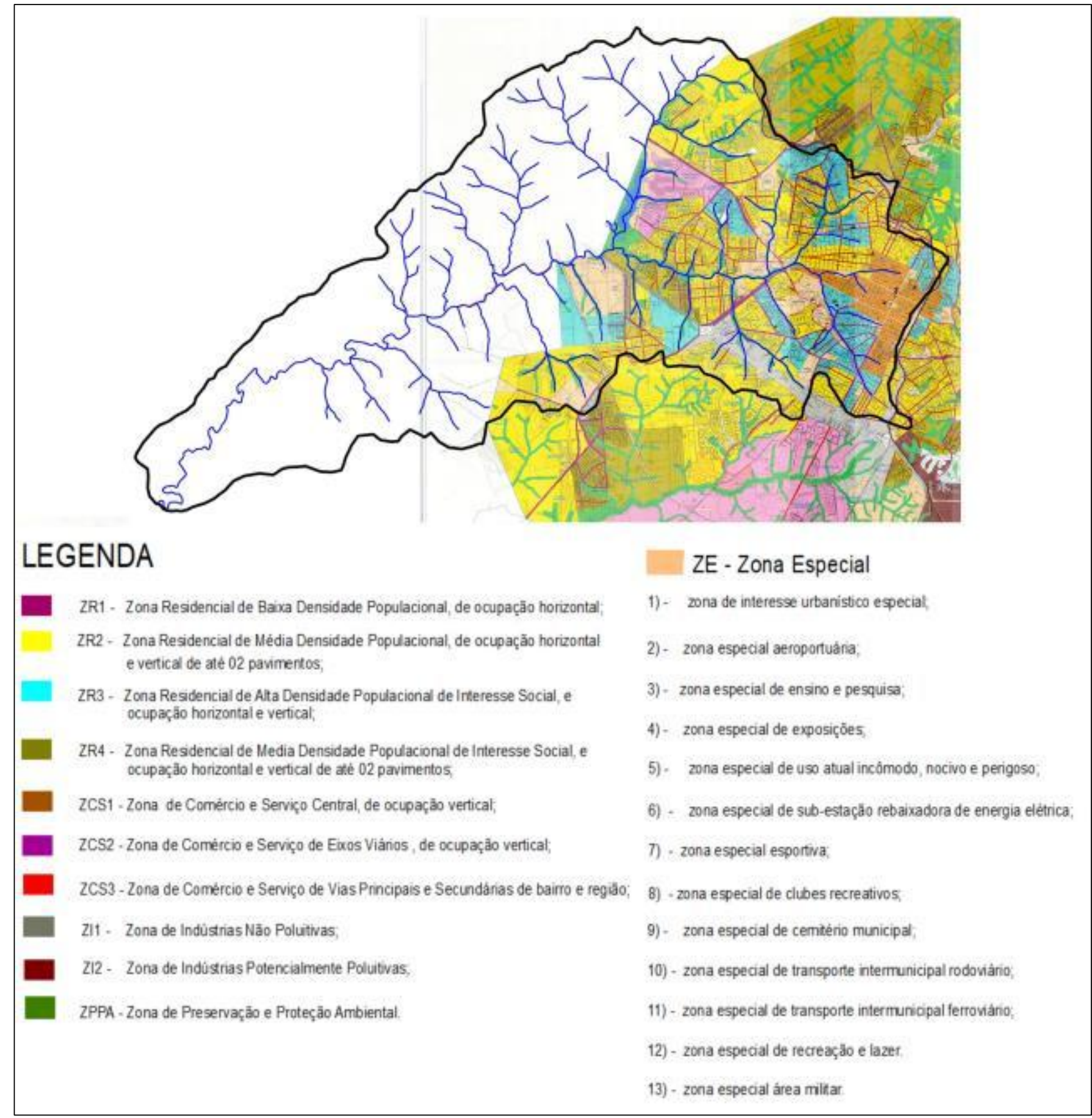

Fonte: Prefeitura Municipal de Presidente Prudente (2011), modificado pelos autores. 
Figura 5. Mapa de localização dos pontos amostrais

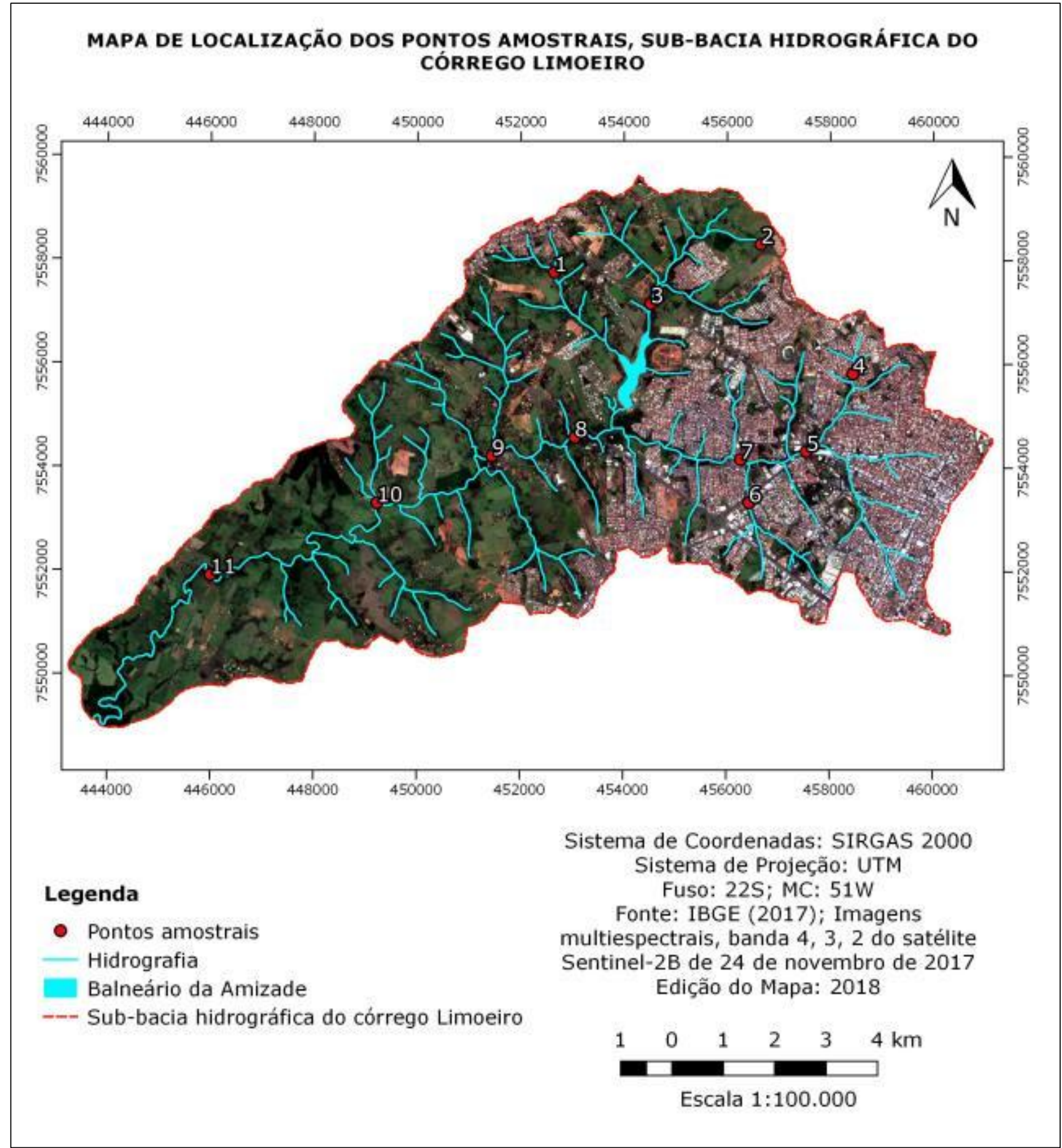

Fonte: Autores (2018). 
Quadro 1. Imagens e Descrição dos pontos amostrais.

\begin{tabular}{|c|c|c|c|}
\hline Ponto & $\begin{array}{l}\text { Foto do local de } \\
\text { amostragem }\end{array}$ & $\begin{array}{l}\text { Localização dos pontos } \\
\text { amostrais em imagem do } \\
\text { Google Eath }\end{array}$ & Descrição do ponto de amostragem \\
\hline 1 & & & $\begin{array}{l}\text { Localizado no município de Álvares Machado, possui mata em seu entorno, } \\
\text { todavia encontra-se com processos erosivos, tendo árvores caídas. Este ponto } \\
\text { sofre influência da área urbana de Álvares Machado, sendo possível visualizar } \\
\text { uma grande quantidade de resíduos dentro do curso d'água e no seu entorno, } \\
\text { tais como pneus, sacos plásticos, utensílios domésticos, dentre outros. }\end{array}$ \\
\hline 2 & & & $\begin{array}{l}\text { Corresponde a nascente do córrego Limoeiro. Sofre influência de área } \\
\text { residencial de Presidente Prudente, com média densidade populacional. } \\
\text { Encontra-se em propriedade privada, com criação de equinos. As áreas de } \\
\text { preservação permanente encontram-se totalmente degradadas, com intensos } \\
\text { processos erosivos. Observa-se também o pisoteio de animal ao entorno do } \\
\text { curso hídrico. }\end{array}$ \\
\hline 3 & & & $\begin{array}{l}\text { Encontra-se a cerca de } 3 \mathrm{~km} \text { de distância da nascente do córrego Limoeiro, } \\
\text { próximo à Rodovia Arthur Boigues Filho que liga os municípios de Presidente } \\
\text { Prudente e Álvares Machado. Sofre influência urbana de áreas destinadas à } \\
\text { média e baixa densidade populacional e de área destinada a zona especial. } \\
\text { suas matas ciliares encontram-se parcialmente degradadas e há bolsões de } \\
\text { areia dentro do córrego. Este ponto fica antes do balneário da Amizade, local } \\
\text { destinado a recreação aquática da população. }\end{array}$ \\
\hline
\end{tabular}




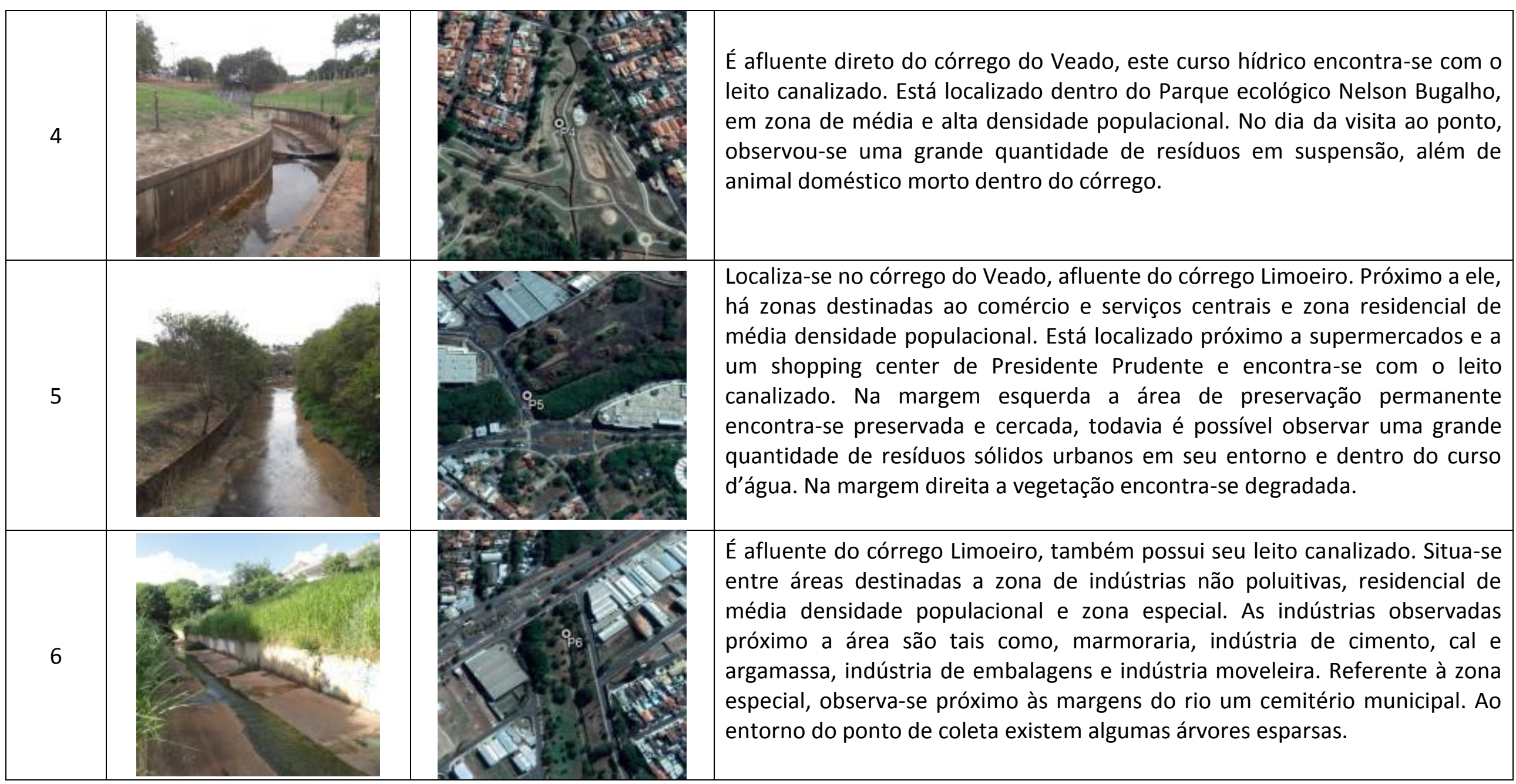




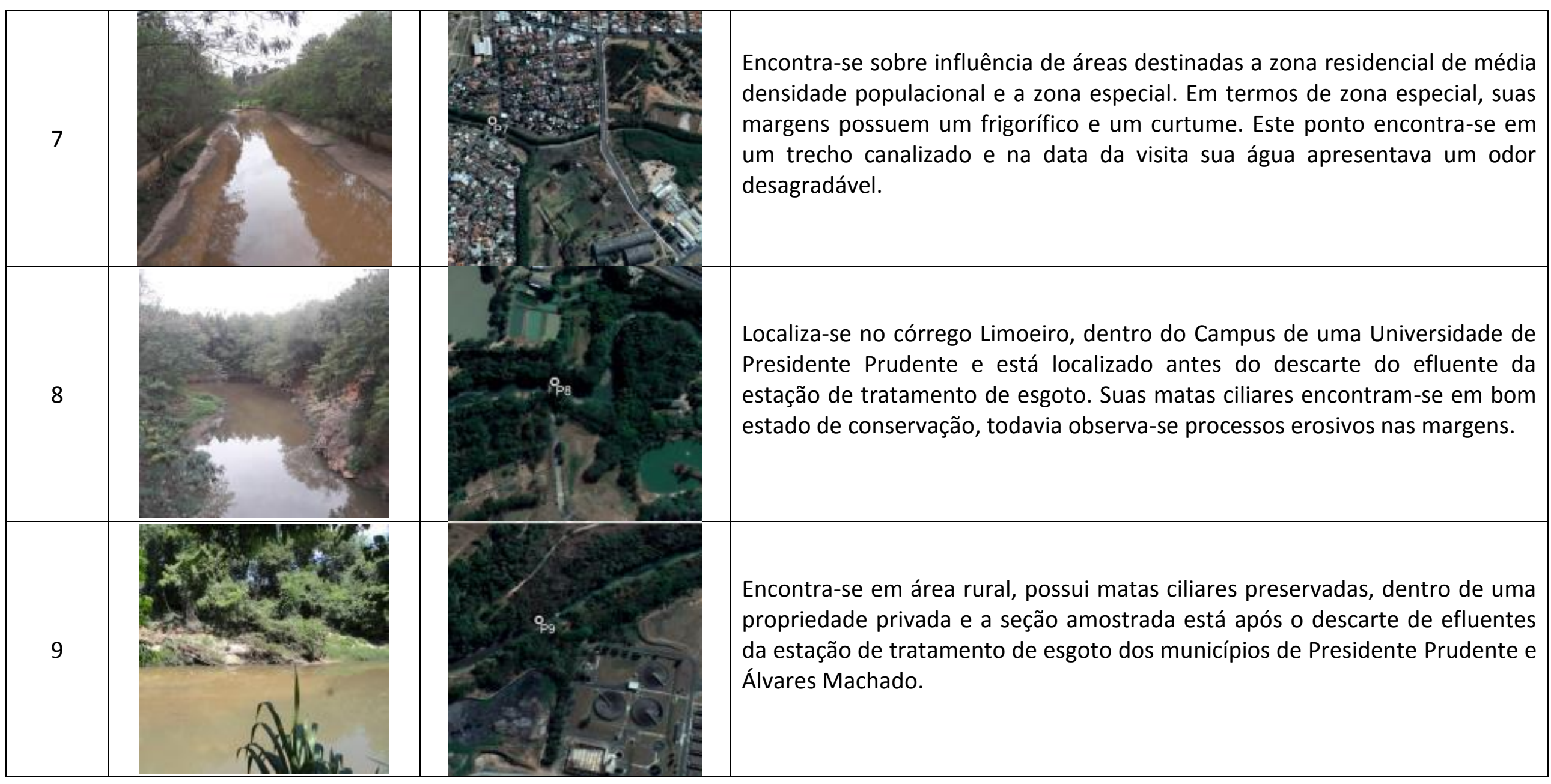




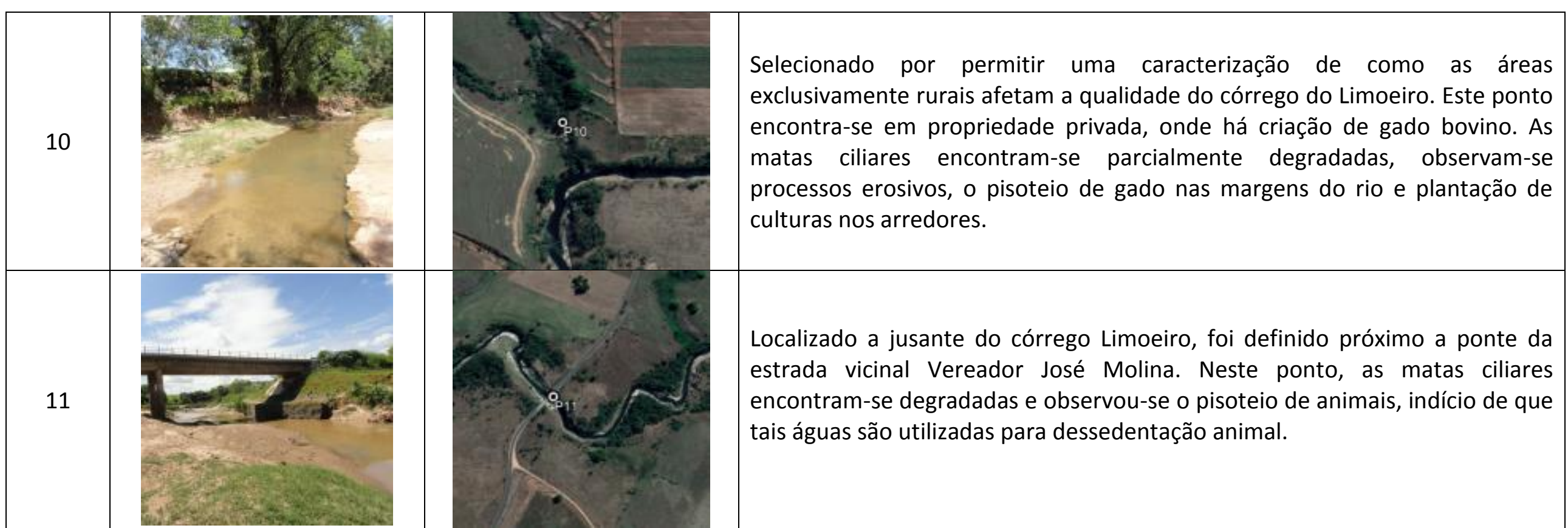

Fonte: Autores (2018). 


\section{DISCUSSÃO}

Os mapas de uso e ocupação do solo e de zoneamento urbano são importantes para a definição dos pontos amostrais. Isso se confirma pelo estudo de caso, pois tais mapas ajudaram a entender a dinâmica da sub-bacia hidrográfica do córrego Limoeiro, e onde se encontram as principais fragilidades quanto à poluição ou contaminação dos recursos hídricos superficiais. Além disso, a decisão de coletar água em pontos no rio e seus afluentes principais, estando distribuídos entre área rural e urbana, permite futuramente a verificação ou não de um padrão de contaminação entre essas áreas distintas.

A estratégia de realizar visita a campo permite definir a acessibilidade dos pontos bem como sua caracterização. Em estudos como o de Santos e Barbosa (2013); Rabelo, Neto e Freire (2015); Silva Corrêa e Ribeiro de Araújo (2016); Rabelo, Biscaíno Neto e Freire (2016); e de Silva e De Araújo (2017) sobre o córrego do limoeiro nota-se a escolha de alguns pontos correlatos, bem como a fragilidade destes pontos à degradação ambiental, devido a forma de uso e ocupação do solo nos seus entornos.

Vale ressaltar que se buscou em trabalhos realizados, algumas informações que auxiliassem na caracterização de possíveis fontes poluidoras na bacia do córrego Limoeiro, bem como outras informações, como recomenda a CETESB (2011).

Definidas e realizadas estas etapas, pode-se buscar cumprir um objetivo ainda maior, o de monitoramento dos recursos hídricos. Assim, é possível verificar se as características climáticas de cada estação do ano afetam na qualidade de águas superficiais, bem como averiguar se existe um padrão de qualidade entre as águas influenciadas pelas diferentes formas de uso e ocupação do solo.

\section{CONSIDERAÇÕES FINAIS}

A partir dos procedimentos metodológicos apresentados e do estudo de caso realizado, concluímos que o fluxo de trabalho é uma proposta efetiva para auxiliar na execução das etapas de definição de pontos amostrais, coleta e conservação de amostras de água. Concluímos que o uso das geotecnologias, como o SIG QGIS e as imagens de satélite, é ferramenta fundamental nesse processo de análise da qualidade da água, pois apoia diversas etapas do planejamento da amostragem dos pontos. Além disso, através destas ferramentas, notase a facilidade em identificar a dinâmica da área de interesse, bem como nortear a chegada e acesso aos pontos de coleta.

Recomendados a partir deste planejamento de amostragem, o monitoramento sazonal das águas superficiais da sub-bacia hidrográfica do córrego Limoeiro, de modo a servir como base para elaboração de planejamento de como gerenciar estes recursos.

\section{REFERÊNCIAS}

APHA. Standard Methods for the examination of water and wastewater. 22. ed. Washington, DC: [s.n.], 2012.

COMPANHIA AMBIENTAL DO ESTADO DE SÃO PAULO - CETESB. Guia nacional de coleta e preservação de amostras: água, sedimento, comunidades aquáticas e efluentes líquidos. São Paulo: CETESB; Brasília: ANA, 2011.

SANTOS, F. R.; BARBOSA, H. P. Um estudo comparativo de dois córregos urbanos em Presidente Prudente (SP): Colônia Mineira e Limoeiro. Geografia em Atos (Online), v. 2, n. 13, p. 68-89, 2013.

FERNANDES, M. R.; SILVA, J. C. Programa estadual de manejo de sub-bacias hidrográficas: Fundamentos e estratégias. Belo Horizonte: EMATERMG, 1994. 24p. 
LONGLEY, P. A.; GOODCHILD, M. F.; MAGUIRE, D. J.; RHIND, D. W. Sistemas e Ciência da Informação Geográfica. 3. ed. Porto Alegre: Bookman, 2013.

PAIVA, J. B. D.; PAIVA, E. M. C. D. (ed.). Hidrologia aplicada à gestão de pequenas Bacias Hidrográficas. Porto Alegre: ABRH, 2001.

PREFEITURA MUNICIPAL DE PRESIDENTE PRUDENTE - PMPP. Mapas e informações geográficas. Presidente Prudente, 2011. Disponível em: http://www.presidenteprudente.sp.gov.br/si te/central_mapas.xhtml. Acesso em: $7 \mathrm{dez}$. 2017.

RABELO, G. C.; BISCAÍNO NETO, J.; FREIRE, R. Concentração de matéria orgânica nas águas da porção urbana da bacia hidrográfica do Córrego do Limoeiro. Periódico Eletrônico Fórum Ambiental da Alta Paulista, v. 12, n. 3, 2016. https://doi.org/10.17271/198008271232016 $\underline{1409}$

RABELO, G. C.; BISCAINO NETO, J. B.; FREIRE, R. Qualidade das águas dos córregos urbanos de Presidente Prudente: análise preliminar. Revista Nacional de Gerenciamento de Cidades, v. 3, n. 15, 2015. https://doi.org/10.17271/231884723152015 $\underline{990}$

RODRIGUES, T. W. P. et al. Delineamento amostral em reservatórios utilizando imagens landsat-8/OLI: um estudo de caso no Reservatório de nova Avanhandava (Estado de São Paulo, Brasil). Boletim de Ciências Geodésicas. Curitiba, v. 22, n. 2, p. 303-323, abr./jun, 2016. Disponível em: http://www.scielo.br/scielo.php?script=sci_a rttext\&pid=S1982$21702016000200303 \& \operatorname{lng}=p t \& n r m=$ iso. Acesso em: 31 jul. 2018.

SILVA CORRÊA, T.; ARAÚJO, R. Estudo de autodepuração: o caso do córrego do
Limoeiro, Presidente Prudente - SP. Colloquium Exactarum, v. 7, n. 3, p. 48-55, $2015 . \quad$ Disponível em: file://C:/Users/bib.guaruja08/Downloads/ES TUDO_DE_AUTODEPURACAO_O_CASO_DO_ CORREGO_DO_LIMOE.pdf Acesso em: 4 jun. 2018. https:doi.org//

10.5747/ce.2015.v07.n3.e128

SANTOS, F. R.; BARBOSA, H. P. Um estudo comparativo de dois córregos urbanos em Presidente Prudente (SP): Colônia Mineira e Limoeiro. Geografia em Atos (Online), v. 2, n. 13, p. 68-89, 2013.

SILVA, M. A.; DE ARAÚJO, R. R. Análise temporal da qualidade da água no córrego limoeiro e no rio Pirapozinho no Estado de São Paulo-Brasil. Formação (Online), v. 1, n. 24, p. 182-203, 2017.

THEOBALD, D. M. et al. Using GIS to generate spatially balanced random survey designs for natural resource applications. Environmental Management, v. 40, n. 1, p. 134-146, 2007. https://doi.org/10.1007/s00267-005-0199-x

TUNDISI, J. G.; MATSUMURA-TUNDISI, T. Recursos hídricos no século XXI. Oficina de Textos, 2011.

ZAHED FILHO, K. Bacia hidrográfica. In: PORTO, R. L. L. (org.). Fundamentos para a Gestão da Água. São Paulo: Secretaria do Meio Ambiente, 2012. 